\title{
Pengalaman Pengobatan dan Kecemasan pada pasien Kanker di Awal Bros Hospital Makassar
}

\author{
Muhammad Saddad Tanrewali ${ }^{1}$, Wahyuningsih ${ }^{1}$ \\ ${ }^{1}$ Universitas Patria Artha
}

Keywords :

Treatment Experience, Anxiety

\section{Kontak :}

Muhammad Saddad Tanrewali Email : m.saddad@patria-artha.ac.id Universitas Patria Artha

\section{Vol 2 No 1 September 2019}

DOI: https://doi.org/10.31605/jhealt.v2i1

(C)2019J-Healt

ini adalah artikel dengan akses terbuka dibawah licenci CC BY-NC-4.0

https://creativecommons.org/licenses/by-nc/4.0/

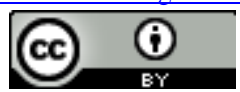

\begin{abstract}
Abstrak
Penyakit kanker masih menjadi masalah kesehatan serius di Indonesia. Kementerian Kesehatan (Kemkes) menyebutkan prevalensi penyakit kanker mengalami peningkatan dalam lima tahun terakhir. Menurut Riset Kesehatan Dasar (Riskesdas) tahun 2018, prevalensi kanker di Indonesia mencapai 1.79 per 1000 penduduk, naik dari tahun 2013 sebanyak 1.4 per 1000 penduduk. Riset ini juga menemukan, prevalensi tertinggi ada di Yogyakarta sebanyak 4.86 per 1000 penduduk, disusul Sumatera Barat 2.47, dan Gorontalo 2.44. Tujuan Penelitian Untuk Menganalisis Faktor yang berhubungan dengan tingkat Kecemasan pasien Kanker selama pengobatan di Awal Bros Hospital Makassar. Sampel yang diteliti adalah sebanyak 35 responden, desain analaitik dengan pendekatan cross sectional, dan menggunakan alat ukur tingkat kecemasan HARS (Hamilton Anxiety Rating Scale). Hasil menunjukkan bahwa Ada hubungan antara pengalaman pengobatan sebelumnya dengan tingkat kecemasan responden selama menjalani Pengobatan dengan nilai $\mathrm{p}$ - nilai $\mathrm{P}(0.013)$ atau $<0.05$, Pengalaman awal pasien dalam pengobatan merupakan pengalaman-pengalaman yang sangat berharga yang terjadi pada individu terutama untuk masa-masa yang akan datang. Pengalaman awal ini sebagai bagian penting dan bahkan sangat menentukan bagi kondisi mental individu di kemudian hari. Apabila pengalaman individu tentang kemo terapi kurang, maka cenderung mempengaruhi peningkatan kecemasan saat menjalani Pengobatan.
\end{abstract}

\section{Abstract}

Cancer is still a serious health problem in Indonesia, Ministry of Health said the prevalence of cancer has increased in the last five years. According to the Basic Health Research (Riskesdas) in 2018, the prevalence of cancer in Indonesia reaches 1.79 per 1000 population, up from 2013 as much as 1.4 per 1000 population, This research also found that the highest prevalence was in Yogyakarta as much as 4.86 per 1000 population, followed by West Sumatra 2.47, and Gorontalo 2.44. Research Objectives To Analyze Factors related to the Anxiety Level of Cancer Patients during Treatment at the Beginning of the Awal Bros Makassar Hospital, The sample studied was 35 respondents, Analaitic design with cross sectional approach, and using HARS (Hamilton Anxiety Rating Scale) anxiety level measurement tool. The results show that there is a relationship between previous treatment experience with the level of anxiety of respondents during treatment with a p-value of $P(0.013)$ or $<0.05$, The patient's initial experience in treatment is very valuable experiences that occur in individuals, especially for the future. This initial experience as an important and even crucial part for the mental state of the individual in the future. If an individual experience about chemo therapy is lacking, it tends to affect the increase in anxiety while undergoing treatment. 


\section{PENDAHULUAN}

Penyakit kanker masih menjadi masalah kesehatan serius di Indonesia. Kementerian Kesehatan (Kemkes) menyebutkan prevalensi penyakit kanker mengalami peningkatan dalam lima tahun terakhir. Menurut Riset Kesehatan Dasar (Riskesdas) tahun 2018, prevalensi kanker di Indonesia mencapai 1.79 per 1000 penduduk, naik dari tahun 2013 sebanyak 1.4 per 1000 penduduk. Riset ini juga menemukan, prevalensi tertinggi ada di Yogyakarta sebanyak 4.86 per 1000 penduduk, disusul Sumatera Barat 2.47, dan Gorontalo 2.44. (Kemenkes RI, 2018).

Data lainnya, Globocan tahun 2018 menunjukkan kejadian penyakit kanker di Indonesia sebanyak 136.2 per 100.000 penduduk. Angka ini menempatkan Indonesia di urutan kedelapan dengan kasus terbanyak di Asia Tenggara, dan peringkat ke-23 se-Asia. Angka kejadian tertinggi pada laki-laki adalah kanker paru sebesar 19,4 per 100.000 penduduk dengan rata-rata kematian 10,9 per 100.000 penduduk. Disusul kanker hati dengan kejadian sebesar 12,4 per 100.000 penduduk, dan rata-rata kematian 7,6 per 100.000 penduduk. Sebagian masyarakat masih beranggapan bahwa penyakit kanker membuat krisis hidup yang amat besar. Reaksi pada sebagian orang yang menderita kanker sangat bervariasi, misalnya syok, takut, cemas, perasaan berduka, marah, sedih dan sampai ada yang menarik diri, Perasaan cemas pada pasien kanker karena takut akan dampak yang terjadi, misalnya perubahan body image dan kematian (Muntaha 2017).

Berdasarkan data yang diperoleh di Awal Bros Hospital pada tahun 2016 terdapat 211 total kasus baru pasien kanker yang menjalani kemoterapi dengan jumlah persiklus sebanyak 730 pasien. Dari 211 total kasus baru, 145 diantaranya pasien rawat inap, 65 pasien rawat jalan. Sedangkan pada tahun 2017, total kasus baru pasien kanker meningkat dari 211 menjadi 320 pasien. Dengan jumlah persiklus sebanyak 1416 pasien. Dari 397 pasien, 251 diantaranya pasien rawat inap, 69 pasien rawat jalan Jadi total jumlah pasien kanker yang menjalani kemoterapi dari tahun 2016 sampai 2017 berjumlah 531 pasien. Jumlah tersebut meliputi jumlah pasien kanker dengan semua jenis pasien kanker. (sumber : data primer).

Berdasarkan penelitian yang dilakukan oleh Muntaha (2017) di RS Pendidikan universitas Hasanuddin yaitu Tidak ada hubungan antara tingkat pendidikan responden dengan tingkat kecemasan, Tidak ada hubungan antara akses informasi dengan tingkat kecemasan responden selama pemberian obat kemoterapi, Tidak ada hubungan antara tingkat sosial ekomonomi dengan tingkat kecemasan responden selama pemberian obat kemoterapi, Tidak ada hubungan antara komunikasi terapeutik dengan tingkat kecemasan responden selama pemberian obat kemoterapi.

Berdasarkan pengkajian pra penelitian yang dilakukan peneliti di Awal Bros Hospital Makassar baik melalui wawancara maupun observasi langsung, sebagian besar pasien kanker yang melakukan kemoterapi mengalami kecemasan. Mereka beranggapan bahwa kemoterapi banyak menimbulkan efek samping seperti hilang selera makan. lemas, mual, muntah, gangguan pencernaan, sariawan gangguan otot dan saraf, penurunan sel darah putih atau leukopen serta adanya nyeri Sehingga ketidaknyamanan itu membuat mereka cemas akan terapi ini.

Tujuan Penelitian ini adalah untuk menganalisis Faktor yang berhubungan dengan tingkat kecemasan pasien kanker selama pengobatan di Awal Bros Hospital Makassar

\section{METODE}

Penelitian ini menggunakan desain analaitik dengan pendekatan cross sectional, dan menggunakan alat ukur tingkat kecemasan HARS (Hamilton Anxiety Rating Scale). Lokasi Penelitian ini dilaksanakan di Awal Bros Hospital Makassar, Penelitian ini 
dilaksanakan pada bulan Sepanjang Tahun 2019 Populasi pada penelitian ini adalah semua pasien kanker yang menjalani Pengobatan sebanyak 35 sampai 50 orang, Sampel pada penelitian ini adalah semua Pasien Kanker yang menjalani Pengobatan di Awal Bros Hospital Makassar, Teknik pengambilan data pada penelitian ini menggunakan teknik total Sampling dimana pasien bersedia menjadi objek penelitian dan dalam keadaan sadar. pengkajian pra penelitian yang dilakukan peneliti di Awal Bros Hospital Makassar baik melalui wawancara maupun observasi langsung

\section{HASIL}

Penelitian ini dilakukan di Awal Bros Hospital Makassar dengan jumlah sampel sebanyak 35 orang

\section{Analisis Univariat}

Tabel 1 Distribusi responden berdasrkan Usia

\begin{tabular}{ccc}
\hline Usia & n & \% \\
\hline Berisiko & 23 & 65.7 \\
Tidak berisiko & 12 & 34.3 \\
\hline Total & & $\mathbf{1 0 0 . 0}$ \\
\hline Sumber: data primer & &
\end{tabular}

Diketahui dari total 35 sampel responden sebanyak 23 orang $(65.7 \%)$ dalam kategori berisiko yaitu dengan rentang usia 21-45 tahun, sedangkan kategori tidak berisiko rentang usia dibawah 21 tahun dan diatas 45 tahun, sebanyak 12 orang (34.3\%).

Diketahui dari total sample sebanyak 35 orang, terdapat sebanyak 22 orang $(62.9 \%)$ dalam kategori berisiko atau belum pernah menjalani kemoterapi sebelumnya, dan sebnyak 13 orang (37.1\%) dalam kategori ridak berisiko atau pernah menjalani kemoterapi sebelumnya.

Tabel 2 Distribusi responden berdasrkan pengalaman pengobatan sebelumnya

\begin{tabular}{|c|c|c|}
\hline $\begin{array}{l}\text { pengalaman } \\
\text { pengobatan } \\
\text { sebelumnya }\end{array}$ & $\mathbf{n}$ & $\%$ \\
\hline Berisiko & 22 & 62.9 \\
\hline Tidak berisiko & 13 & 37.1 \\
\hline Total & 35 & 100.0 \\
\hline \multicolumn{3}{|c|}{ Sumber data : data primer } \\
\hline \multicolumn{3}{|c|}{$\begin{array}{l}\text { Diketahui dari total Distribusi responden } \\
\text { berdasarkan pengalaman pengobatan } \\
\text { sebelumnya sample sebanyak } 35 \text { responden, } \\
\text { terdapat } 14 \text { orang ( } 40 \% \text { ) berisiko atau tidak } \\
\text { dapat mengakses infromasi tentang } \\
\text { pengobatan dengan baik dari sumber yang } \\
\text { ada, dan } 21 \text { orang }(60 \%) \text { tidak berisiko yang } \\
\text { berarti dapat mengakses informasi mengenai } \\
\text { pengobatan dari berbagai sumber. }\end{array}$} \\
\hline
\end{tabular}

\section{Analisis Bivariat}

Tabel 3 Hubungan pengalaman pengobatan dengan tingkat kecemasan responden

\begin{tabular}{|c|c|c|c|c|c|c|c|}
\hline \multirow{2}{*}{$\begin{array}{l}\text { Pengalaman } \\
\text { kemoterapi } \\
\text { responden }\end{array}$} & \multicolumn{4}{|c|}{ Tingkat kecemasan } & \multicolumn{2}{|c|}{ jumlah } & \multirow{2}{*}{$\begin{array}{l}\text { Nilai } \\
\quad p\end{array}$} \\
\hline & Tinggi (n) & $\%$ & Rendah (n) & $\%$ & $\mathrm{n}$ & $\%$ & \\
\hline Berisiko & 11 & 50.0 & 11 & 50.0 & 22 & 100 & 0.013 \\
\hline Tidak berisiko & 1 & 7.7 & 12 & 92.3 & 13 & 100 & \\
\hline total & 12 & 34.3 & 23 & 65.7 & 35 & & \\
\hline
\end{tabular}


Berdasarkan tabel diatas dapat diketahui bahwa dari total keseluhan sampel sebanyak 35 responden terdapat 11 orang $(50 \%)$ dengan pengalaman pengobatan berisiko memiliki tingkat kecemasan tinggi, sebanyak 11 orang $(50 \%)$ dengan pengalaman pengobatan berisiko memiliki tingkat kecemasan rendah, dan terdapat 1 orang $(7.7 \%)$ dengan pengalaman pengobatan tidak berisiko memiliki tingkat kecemasan tinggi, dan sebanyak 12 orang $(92.3 \%)$ dengan pengalaman pengobatan tidak berisiko memiliki tingkat kecemasan rendah. Hasil analisis statistik diperoleh nilai $\mathrm{P}(0.013)$ atau $<0.05$, berarti ada hubungan antara pengalaman pengobatan sebelumnya dengan tingkat kecemasan pasien kanker selama menjalani pengobatan di Awal Bros Hospital Makassar

\section{PEMBAHASAN}

Hasil penelitian ini menunjukkan bahwa dari total keseluhan sampel sebanyak 35 responden terdapat 11 orang $(31.4 \%)$ dengan pengalaman pengobatan berisiko memiliki tingkat kecemasan tinggi, sebanyak 11 orang (31.4\%) dengan pengalaman pengobatan berisiko memiliki tingkat kecemasan sedang, dan terdapat 1 orang dengan pengalaman pengobatan tidak berisiko memiliki tingkat kecemasan tinggi, dan sebanyak 7 orang (20.0\%) dengan pengalaman pengobatan tidak berisiko memiliki tingkat kecemasan sedang, dan 5 orang (14.3\%) dengan pengalaman pengobatan tidak berisiko memiliki tingkat kecemasan rendah. Hasil analisis statistik diperoleh nilai $\mathrm{P}(0.013)$ atau $<0.05$, berarti ada hubungan antara pengalaman pengobatan sebelumnya dengan tingkat kecemasan pasien kanker selama

Pengalaman awal pasien dalam pengobatan merupakan pengalaman-pengalaman yang sangat berharga yang terjadi pada individu terutama untuk masa-masa yang akan datang. Pengalaman awal ini sebagai bagian penting dan bahkan sangat menentukan bagi kondisi mental individu di kemudian hari.Apabila pengalaman individu tentang kemo terapi kurang, maka cenderung mempengaruhi peningkatan ke cemasan saat menghadapi tindakan kemoterapi.

Sejalan dengan penelitian yang dilakukan (Dewi 2010) bahwa pengalaman dalam pengobatan sangat berpengaruh dalam menurunkan tingkat kecemasan, pengalaman sebelumnya menjadi pelajaran dalam menurunkan kecemasan sangat berbeda dengan orang yang baru akan menjalaninya.

Pengalaman masa lalu baik yang positif maupun negative dapat mempengaruhi mekanisme koping, keberhasilan masa lalu dapat membantu individu untuk mengembangkan keterampilan menggunakan koping, kegagalan mekanisme koping dapat menyebabkan maladaptive terhadap stressor tertentu. Sejalan penelitian yang dilakukan (Muntaha 2017) terdapat pengaruh pengalaman pasien tentang kemoterapi terhadap tingkat kecemasan pasien kemoterapi di RSP Universitas Hasanuddin, Dengan pengalaman pengobatan, usia sangat menentukan kepribadian seseorang dalam menjalani pengobatan.

\section{KESIMPULAN}

Berdasarkan hasil penelitian yang telah dilakukan di Awal Bros Hospital Makassar Ada hubungan antara pengalaman pengobatan sebelumnya dengan tingkat kecemasan responden selama menjalani Pengobatan dengan nilai $p$ - Value $=0.013$

\section{SARAN}

Berdasarkan kesimpulan diatas peneliti dapat menyarankan sebagai berikut: Perlu lebih mengembangkan program pelayanan kesehatan berupa pendidikan atau penyuluhan kepada masyarakat (pasien menjalani kemoterapi) dalam menjalankan asuhan keperawatan 


\section{DAFTAR PUSTAKA}

Abdul Muhith. 2018. Aplikasi Komunikasi Terapeutik Nursing dan Health. Refika Adiatma. Jakarta.

Dewi. 2010.Skripsi.faktor-faktor yang mempengaruhi tingkat kecemasan pasien yang akan menghadapi operasi RSUP Fatmawati

Hamilton Rating Scale For Anxiety (HARS) Universitas. Cara menghitung skala hars. http://repository.maranatha.edu/2088/2/061 0067_Appendices.pdf. Diakses pada 26 Februari 2018.

Infodatin. Pusat data dan informasi kementrian kesehatan RI. (2015). Situasi penyakit kanker. Stop kanker.

http://www.depkes.go.id/resources/download/ pusdatin/infodatin/infodatin-kanker.pdf. Diakses pada tanggal 20 Februari 2018.

International Agency for Research on Cancer (IARC) / WHO.(2012). Estimated cancer incidence, mortality, and prevalence worldwide in 2012. GLOBOCAN. Http://globocan.iarc.fr/Pages/fact_sheets_p opulation.aspx. Diakses tanggal 2 November 2017

Kumala Sari. 2018. Hubungan Dukungan Keluarga Terhadap Kecemasan Pasien Kanker Serviks menjalani Kemoterapi. Fakultas Ilmu Kesehatan Universitas Muhammadiyah Surakarta

Kementerian Kesehatan RI. (2013). Riset Kesehatan Dasar (RISKESDAS). Jakarta: Badan Litbang Kemenkes RI.

Kementerian Kesehatan RI. (2015). Situasi Penyakit Kanker.Jakarta : Pusat Data dan Informasi

Kementerian Kesehatan RI. (2018). Situasi Penyakit Kanker.Jakarta : Pusat Data dan Informasi
Lisa Mutiara, Tingkat Kecemasan Mahasiswa Keperawatan dalam Menghadapi Ujian Berbasis Computer Based Test Jurnal Ilmiah Ilmu-ilmu Kesehatan, Vol 16 No 2

Maya Sari. 2017. Hubungan Kepatuhan Menjalani Kemoterapi dengan Kualitas Hidup Pasien Kanker Serviks di RSUD DR Moewardi Surakarta Fakultas Ilmu Kesehatan Universitas Muhammadiyah Surakarta

Rahmiati. 2017 Gambaran Faktor-faktor yang berhubungan dengan Kecemasan Pasien Kanker Payu Dara dalam menjalani Kemoterapi. Jurnal Pendidikan Keperawatan Indonesia.Universitas Padjajaran. Vol. 3 No.2

Reissa Nur Fauziah 2016. Kecemasan Penderita Kanker. Fakultas Ilmu Kesehatan Universitas Muhammadiyah Surakarta

Saddad Tanrewali.2018.Intervensi Spritual Care dalam Menangani Kecemasan Keluarga Penderita Kanker.Patria Artha Journal of Nursing Science.Vol2.(2)

Wikipedia. (2017). Kemoterapi. Jakarta :. https://id.wikipedia.org/wiki/Kemoterapi.

World Health Organization. (2007). Prevention, cancer control: knowledge into action: WHO guide for effective programmes: module II. Geneva: World Health Organization.

Ciji catur Wulandari .2015.Dinamkika regulasi emosi pada pasien kanker payu dara (studi kasus pada pasien Kanker Payu dara di Yogyakarta. universitas islam negeri sunan kali jaga Yogyakarta

Yasirul Muntaha.2017. Hubungan antara faktor-faktor yang berhubungan dengan tingkat kecemasan pasien kanker selama pemberian obat kemoterapi di RSP Unhas.

Yusuf. 2017. Buku Ajar Keperawatan Kesehatan Jiwa. Salemba Medika. Jakarta 